\title{
Jones-Dole Coefficients and Conductivity Studies on Electrolyte Solutions of Magnesium Borohydride in Mixtures of 1,2-Dimethoxyethane-Propylene Carbonate and 2-Methoxyethyl Ether-Propylene Carbonate
}

\author{
John N. Obowu \\ Department of Pure and Industrial Chemistry \\ University of Port Harcourt, P.M.B. 5323, Choba \\ Port Harcourt, Nigeria. \\ Millicent U. Ibezim-Ezeani* \\ Department of Pure and Industrial Chemistry \\ University of Port Harcourt, P.M.B. 5323, Choba \\ Port Harcourt, Nigeria. \\ Augustine A. Abia \\ Department of Pure and Industrial Chemistry \\ University of Port Harcourt, P.M.B. 5323, Choba \\ Port Harcourt, Nigeria.
}

\begin{abstract}
The study on the competing influences of ion-ion, ion-dipole and dipole-dipole interactions by the species in magnesium borohydride $\left[\mathrm{Mg}\left(\mathrm{BH}_{4}\right)_{2}\right]$ organic electrolyte solutions is reported. The organic electrolyte solutions were formulated by dispersing $\mathrm{Mg}\left(\mathrm{BH}_{4}\right)_{2}$ salt concentrations of $0.01,0.05,0.10$ and $0.50 \mathrm{M}$ in mixed solvent systems of 1,2-dimethoxyethane (DME)-propylene carbonate (PC) and 2-methoxyethyl ether (DGM)-propylene carbonate $(P C)$. The density, viscosity, conductivity and dielectric constant were determined at different system compositions. The measured viscosity data varied with concentration according to Jones-Dole equation, while the resolved coefficients revealed that DME-PC and DGM-PC mixtures acted as solvates in the $\mathrm{Mg}\left(\mathrm{BH}_{4}\right)_{2}$ organic electrolyte solutions. The A coefficient values for DME-PC and DGM-PC systems increased progressively with mole fractions over the entire range studied. The B coefficient values for the electrolyte systems were found to exhibit minimum value at 0.822 and 0.095 mole fractions of DME and DGM respectively. The experimental conductivities of the electrolyte solutions measured at temperatures of 298.15, 308.15, 318.15, 328.15 and $338.15 \mathrm{~K}$ increased with increase in temperature from 0 - $50 \%$ vol. composition range; and thereafter, decreased for both DME-PC and DGM-PC systems. This suggests that the most preferred mix ratio of the studied systems is $50 \%$ vol. of component (DME or DGM) for optimum battery performance.
\end{abstract}

Keywords: Battery, Ion-dipole interaction, Columbic efficiency, Electrolyte, Jones-Dole Coefficients

\section{Introduction}

Batteries consist of assembled cells designed solely for the conversion of chemical energy into electrical energy (Hannan et al., 2017). Electrical energy is ubiquitous and its application continues to grow globally. Primarily, electric energy is exploited for heating, lighting and for powering electronics; such as integrated circuit memory retention and biomedical implantable devices. An important battery concept relates to the quantity of load current delivered by the battery and its duration. This is stated as battery capacity (C) and is quoted in Ampere Hours (Ah); for a specific discharge rate to End Point (Output Voltage). The energy density of a cell is quoted in weight $(\mathrm{kg})$ or volume $\left(\mathrm{cm}^{3}\right)$ ratio. Another important battery parameter is the coulombic efficiency, defined as the quotient of the charge that leaves the battery in the course of discharge cycle to the charge that passes into the battery in the course of charging cycle. $100 \%$ columbic efficiency is not achievable owing to charge losses from secondary reactions, such as redox reactions in the battery. Better conductivity advances battery reversibility and lessen the voltage differential between the discharge and charge curves. Higher coulombic efficiency means that the level of irreversible drawback reactions in the cell is reduced. The storage of electrical energy necessitates its conversion to another form of energy. 
In battery systems, the electrolyte serves as the storage medium and when the battery undergoes discharge, redox reactions generate electrical energy that is harvested as electric current at a particular voltage. The borohydrides have substantial content of gravimetric hydrogen. The absorption and desorption temperatures of hydrogen are relatively low for magnesium borohydride $\mathrm{Mg}\left(\mathrm{BH}_{4}\right)_{2}$, spurring immense curiosity and interest (Aurbach et al., 2001 a \& b). The borohydrides are employed as reducing agents in chemical syntheses, since their reducing property fosters stability against electrolytic reduction. The deficiencies in lithium battery systems have created the pathway for magnesium batteries as alternatives. Magnesium batteries offer astoundingly high volumetric capacity, improved safety besides the relative abundance of $\mathrm{Mg}$ metal. To exploit the vast potential offered by $\mathrm{Mg}$ batteries, several hurdles in their electrolyte design must be surmounted for this technology to be feasible (Muldoon et al., 2012). The corrosive nature of perchlorates has been credited to the existence of chlorides in their ions. Traditional electrolytes such as $\mathrm{Mg}\left(\mathrm{ClO}_{4}\right)_{2}$ were reckoned incompatible with magnesium anode owing to the growth of an ion-impeding layer, the consequence of their electrochemical reduction (Pour et al., 2011). The discovery of halide free electrolytes is crucial for advancing technology towards the achievement of a rechargeable Mg battery. Without doubt, the shortages of viable electrolytes and feasible cathode materials have restricted demonstrations of rechargeable $\mathrm{Mg}$ battery systems to the laboratory (Mohtadi \& Mizuno, 2014). Reversible Mg plating / stripping continues to delude many electrolytes. Importantly, it is accepted that the solution coordination structures of $\mathrm{Mg}$ complexes in these electrolytes are essential for reversible $\mathrm{Mg}$ plating / stripping (Muldoon et al., 2012). The stability of metal complexes is aided by coordinating solvent ligands and the stability of $\mathrm{Mg}\left(\mathrm{BH}_{4}\right)_{2}$ coordination structures show no exception to this rule. In the complex $\operatorname{Mg}\left(\mathrm{BH}_{4}\right)_{2} \cdot \mathrm{nL}(\mathrm{L}=$ ligand), ligands are dislodged by another of higher denticity (Bremer et al., 2005). Magnesium borohydride electrolyte was considered for Mg batteries (Mohtadi et al., 2012 a \& b). This choice was made on the assertion that the $\mathrm{BH}_{4}^{-}$was relatively a strong reducing agent and could withstand the reducing vicinity of the $\mathrm{Mg}$ anode. These findings attest to the fact that ionic salts could be adapted to the magnesium metal, if the anion in the salt has sufficient reductive stability. Pioneering work in hydride chemistry recognize that molecular hydrogen complexes participate significantly in metal complex reactivity (Chatt, 1968).

Information bordering on structure property relationship of solutions continues to advance the studies on viscosities of electrolyte solutions. Ion-ion and ion-solvent interactions are of significant interest especially amongst the complexity of interactions that exist between ions in solutions. Viscosity studies on $\mathrm{Mg}\left(\mathrm{BH}_{4}\right)_{2}$ organic electrolyte solutions are useful for understanding interactions at molecular level. Among the main properties of the solvents, low viscosity of DGM and DME and high dielectric constant of PC conduce high conducting electrolytes. It is the interest of this investigation to determine the viscosity and conductivity of $\mathrm{Mg}\left(\mathrm{BH}_{4}\right)_{2}$ electrolytes constituted using the mixed solvent systems of DGM-PC and DME- PC at different conditions of experiment; and to apply the outcome of the study in electrolyte design for high capacity energy source.

\section{Experimental}

\subsection{Materials and Methods}

The solvents procured for this research are DME (99.5\%) and PC (99.5\%) products of BDH Chemical Ltd. England, DGM (99.5\%) product of BASF Chemical Company England and dry $\operatorname{Mg}\left(\mathrm{BH}_{4}\right)_{2}(95 \%)$ product of Sigma Aldrich. The Binary mixtures of DGM \& PC and DME \& PC were constituted by mixing the liquid components in varying percentage of $0 \%, 15 \%, 25 \%, 50 \%, 75 \%, 85 \%$ and $100 \%$ (volume percent). The samples were weighed on HR-120 (A\&D Japan) electronic balance with a precision of $\pm 10^{-4} \mathrm{~g}$. The mole fractions range from 0.125 to 1.000 (DME) and 0.095 to 1.000 (DGM). The density of the solutions (prepared in concentrations of $0.01,0.05,0.1,0.5 \mathrm{M}$ in solvent) was determined with a single stem capillary pycnometer bottle at temperatures of $298.15,308.15,318.15 \mathrm{k}, 328.15 \mathrm{~K}$ and $338.15 \pm 0.01 \mathrm{~K}$. The kinematic viscosity of the solutions was measured at the desired temperature using a suspended ubbelohde viscometer tube ASTM D 446. The experimental solutions were retained at the required temperatures of $298.15,308.15,318.15,328.15 \mathrm{~K}$ and $338.15 \pm 0.01 \mathrm{~K}$ with Koehler electronic thermostat water bath. An electronic timer with precision $\pm 0.01 \mathrm{~s}$ was used to determine the flow time. The conductivity of the solutions was measured with Thermo Scientific Orion conductivity meter (Orion 162A), calibrated with $0.001 \mathrm{M} \mathrm{KCl}$ standard $(147 \mu \mathrm{S} / \mathrm{cm}$ at $298.15,308.15,318.15 .328 .15$ and $338.15 \pm$ $0.01 \mathrm{~K})$. 


\subsection{Data Analysis}

The kinematic viscosity was determined using the equation (Ibezim-Ezeani et al., 2017 a):

$V=k t$

Where $V$ is the Kinematic viscosity, $k$ is the Viscometer constant and $t$ the flow time.

The dynamic viscosity was deduced with the formula:

$\eta=V \rho$

Where $\eta$ is the Dynamic viscosity, $V$ is Kinematic viscosity and $\rho$ density of the liquid.

The viscosity of dilute electrolyte solutions $\left(\eta_{r}\right)$, vary with concentration $(c)$ according to the Jones-Dole equation (Jones \& Dole, 1929):

$\eta_{r}=\frac{\eta_{y}}{\eta_{Q}}=1+A C^{\frac{1}{2}}+B C$

Where $\eta$ and $\eta_{o}$ are the viscosities of solution and solvent in turn, while A and B are the Jones - Dole coefficients. The A and B coefficients symbolize ion-ion interactions and ion-solvent interactions respectively. The parameters $\mathrm{A}$ and $\mathrm{B}$ were obtained by plotting a graph of $\left(\eta_{r}-1\right) /\left(\mathrm{c}^{1 / 2}\right)$ versus $\mathrm{c}^{1 / 2}$ for the $\mathrm{Mg}\left(\mathrm{BH}_{4}\right)_{2}$ salt solutions in the whole composition range of DME-PC and DGM-PC systems at the temperature of 298.15 \pm 0.01 K.

The dielectric constant $\left(\varepsilon_{\text {mix }}\right)$ of the binary solvent mixtures (DME-PC and DGM-PC) were calculated with the equation (Rohdewald \& Molder, 1973):

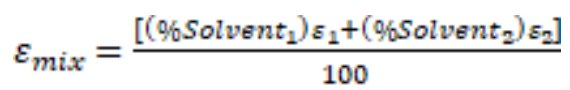

Where $\varepsilon_{1}$ and $\varepsilon_{2}$ are the dielectric constants of pure DME (or DGM) and PC respectively.

\section{Results and Discussion}

\subsection{Jones-Dole Coefficients}

The values of Jones-Dole (A and B) coefficients for the DME-PC (Table 1) and DGM-PC (Table 2) electrolyte solutions are positive over the entire constitution range; suggesting strong solvation of $\mathrm{Mg}^{2+}$ in both solvent systems, which implies that strong ion-solvent arrangements are prevalent. Observations from Tables 1 and 2 reveal that the values of $\mathrm{B}$ coefficients for $\mathrm{Mg}\left(\mathrm{BH}_{4}\right)_{2}$ electrolyte solutions were at their minimal in 0.822 mole fraction of DME and 0.095 mole fraction of DGM. The discourses of previous researchers did expound this behavior, and noted that the solvent mixture with the minimum value of B would be the most structured (Stokes \& Mills, 1965). Therefore, a higher degree of structuring was attained in DGM (15\% vol.) than in DME (85\% vol.).

Results from Table 1, noted that the values of A coefficients increased progressively with increasing composition of DME in the binary mixture, indicating that ion-ion (electrostatic) interactions are reinforced with increasing proportion of DME. Also, from the constitution range of 75 - $100 \%$ vol. DME, ion-ion interactions began to gain preponderance, as the A values compete closely with the B values. This may be credited to the poor solvation of the $\mathrm{Mg}^{2+}$ in the binary mixture over this composition range, resulting in very unstable $\mathrm{Mg}$ complexes. Further observations revealed that ion-solvent interactions are predominant over ion-ion interactions in the range $0-50 \%$ vol. DME. This may be credited to the strong solvation of the $\mathrm{Mg}^{2+}$ ions over this composition range in the binary mixture (DME-PC). Furthermore, the values of B coefficient decreased over the constitution range $0-85 \%$ vol. DME. This suggests that ion-solvent interactions waned as the DME proportion increased, or it may be reported that DME possesses lesser affinity for electrolyte than for PC molecules. That is, solvent-solvent type interactions prevail over ion-solvent type interactions (DME molecules interacting with PC molecules rather than with cations); signifying that ion solvation is limited by strong electrostatic forces as the dielectric constant of the binary mixture decreases. Again, the relatively sizable dipole moment of DME molecules 1.71D (Smith et al., 1995) may become significantly impaired by dispersion forces. This may undermine the prospect of ion-dipole interactions and concurrently foster attraction between dissimilar molecules (DME and PC molecules).

Results from Table 2, showed that ion-solvent interactions predominate over ion-ion interactions in the constitution range $15-85 \%$ vol. DGM. This may be credited to the strong solvation of the $\mathrm{Mg}^{2+}$ over this composition range in the binary mixture (DGM-PC). There was gradual increase in A coefficient values as DGM proportion increased in the mixture; but not to the level of surpassing B coefficient values. 
The B coefficient values also increased over the constitution range $15-50 \%$ vol. DGM in the binary mixture; which suggests that ion-solvent interactions are strengthened as the DGM concentration increased, or it may be stated that DGM has more affinity for the electrolyte than PC molecules; that is, ion-solvent interactions predominate. The values of $\mathrm{B}$ coefficient reach maximum at $50 \%$ vol. DGM and above this threshold, ion solvation is not so appreciably impaired as with the DME binary mixture; probably due to stronger coordination with the tridentate $\mathrm{O}_{2}$ of DGM in the solvated $\mathrm{Mg}^{2+}$ complex. Comparison of the values of the $\mathrm{B}$ coefficient for both systems studied (Tables 1 and 2); reveal that the values are greater in DGM-PC binary mixture than in DMEPC binary mixture. This further corroborates the fact that solvation of the $\mathrm{Mg}^{2+}$ complex is more favorable in DGM-PC system. Again, the relatively sizable dipole moment of DGM molecules 1.91D (Kotera et al., 1962) might not be significantly impaired by dispersion forces when a single DGM molecule orients freely about the $\mathrm{Mg}^{2+}$. Thus, the strength and stability of the ion-dipole attraction is preserved. This stability of the dissolved $\mathrm{Mg}^{2+}$ complex in DGM is a consequence of the superior potency of the ion-dipole attraction relative to dipolar and dispersion forces between dissimilar molecules (DGM-PC).

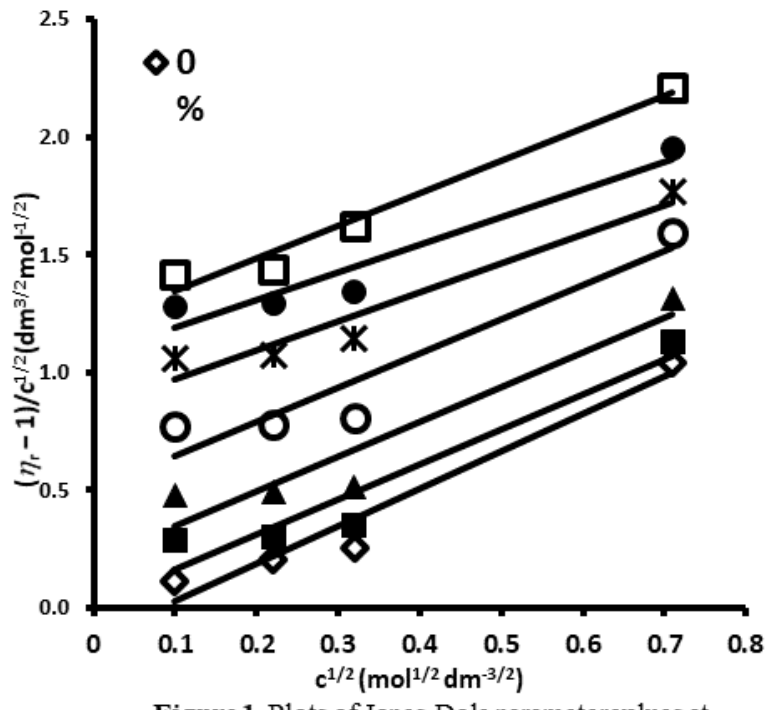

Figure 1. Plots of Jones-Dole parametervalues at different mole fractions of DME

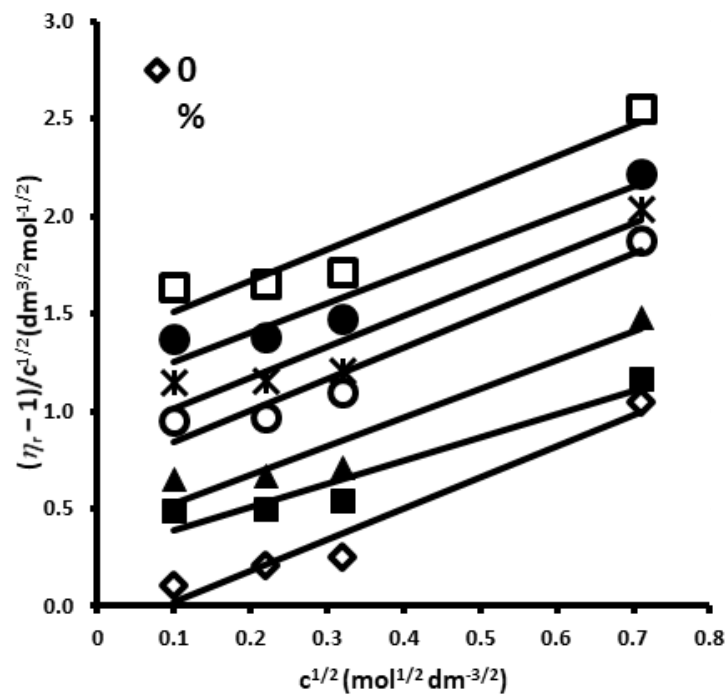

Figure 2. Plots of Jones-Dole parameter values at different mole fractions of DGM

Table 1: Jones-Dole A and B Coefficients at Different Compositions of DME-PC

\begin{tabular}{ccccc}
\hline $\operatorname{DME}(\%)$ & $\mathrm{X}_{1}$ & Linear Equation & $\mathrm{A}\left(\mathrm{dm}^{3 / 2} \mathrm{~mol}^{-1 / 2}\right)$ & $\mathrm{B}\left(\mathrm{dm}^{3 / 2} \mathrm{~mol}^{-1 / 2}\right)$ \\
\hline 0 & 0.000 & $\mathrm{y}=1.596 \mathrm{x}-0.135$ & -0.135 & 1.596 \\
15 & 0.125 & $\mathrm{y}=1.486 \mathrm{x}+0.016$ & 0.016 & 1.486 \\
25 & 0.214 & $\mathrm{y}=1.477 \mathrm{x}+0.201$ & 0.201 & 1.477 \\
50 & 0.448 & $\mathrm{y}=1.456 \mathrm{x}+0.496$ & 0.496 & 1.456 \\
75 & 0.710 & $\mathrm{y}=1.239 \mathrm{x}+0.843$ & 0.843 & 1.239 \\
85 & 0.822 & $\mathrm{y}=1.182 \mathrm{x}+1.069$ & 1.069 & 1.182 \\
100 & 1.000 & $\mathrm{y}=1.382 \mathrm{x}+1.206$ & 1.206 & 1.382 \\
\hline
\end{tabular}


Table 2: Jones-Dole A and B Coefficients at Different Compositions of DGM-PC

\begin{tabular}{ccccc}
$\operatorname{DGM}(\%)$ & $\mathrm{X}_{1}$ & Linear Equation & $\mathrm{A}\left(\mathrm{dm}^{3 / 2} \mathrm{~mol}^{-1 / 2}\right)$ & $\mathrm{B}\left(\mathrm{dm}^{3 / 2} \mathrm{~mol}^{-1 / 2}\right)$ \\
\hline 0 & 0.000 & $\mathrm{y}=1.596 \mathrm{x}-0.135$ & -0.135 & 1.596 \\
15 & 0.095 & $\mathrm{y}=1.199 \mathrm{x}+0.266$ & 0.266 & 1.199 \\
25 & 0.167 & $\mathrm{y}=1.466 \mathrm{x}+0.383$ & 0.383 & 1.466 \\
50 & 0.374 & $\mathrm{y}=1.616 \mathrm{x}+0.680$ & 0.680 & 1.616 \\
75 & 0.643 & $\mathrm{y}=1.582 \mathrm{x}+0.852$ & 0.852 & 1.582 \\
85 & 0.772 & $\mathrm{y}=1.492 \mathrm{x}+1.106$ & 1.106 & 1.492 \\
100 & 1.000 & $\mathrm{y}=1.608 \mathrm{x}+1.345$ & 1.345 & 1.608 \\
\hline
\end{tabular}

Table 3: Experimental Conductivity ( $\kappa$ ) for DME-PC Binary Mixtures at $298.15 \mathrm{~K}$

\begin{tabular}{cccccc}
\hline $\begin{array}{c}\text { DME } \\
(\%)\end{array}$ & $\mathrm{X}_{1}$ & $\begin{array}{c}0.01 \mathrm{M} \\
\mathrm{Mg}\left(\mathrm{BH}_{4}\right)_{2} \\
\kappa\left(\mathrm{mScm}^{-1}\right)\end{array}$ & $\begin{array}{c}0.05 \mathrm{M} \\
\mathrm{Mg}\left(\mathrm{BH}_{4}\right)_{2} \\
\kappa\left(\mathrm{mScm}^{-1}\right)\end{array}$ & $\begin{array}{c}0.10 \mathrm{M} \\
\mathrm{Mg}\left(\mathrm{BH}_{4}\right)_{2} \\
\kappa\left(\mathrm{mScm}^{-1}\right)\end{array}$ & $\begin{array}{c}0.50 \mathrm{M} \\
\mathrm{Mg}\left(\mathrm{BH}_{4}\right)_{2} \\
\kappa\left(\mathrm{mScm}^{-1}\right)\end{array}$ \\
\hline 0 & 0.000 & 0.31 & 0.86 & 1.23 & 4.14 \\
15 & 0.125 & 0.49 & 1.06 & 1.57 & 4.64 \\
25 & 0.214 & 0.60 & 1.20 & 1.77 & 4.96 \\
50 & 0.448 & 0.82 & 1.54 & 1.99 & 5.42 \\
75 & 0.710 & 0.73 & 1.38 & 1.86 & 5.11 \\
85 & 0.822 & 0.55 & 1.15 & 1.64 & 4.73 \\
100 & 1.000 & 0.13 & 0.63 & 1.06 & 4.04 \\
\hline
\end{tabular}

Table 4: Experimental Conductivity $(\kappa)$ for DME-PC Binary Mixtures at different temperatures

\begin{tabular}{|c|c|c|c|c|c|c|c|c|c|}
\hline \multirow[b]{2}{*}{$\begin{array}{c}\text { DME } \\
(\%)\end{array}$} & \multirow[b]{2}{*}{$X_{1}$} & \multicolumn{2}{|c|}{$308.15 \mathrm{~K}$} & \multicolumn{2}{|c|}{$318.15 \mathrm{~K}$} & \multicolumn{2}{|c|}{$328.15 \mathrm{~K}$} & \multicolumn{2}{|c|}{$338.15 \mathrm{~K}$} \\
\hline & & $\begin{array}{c}0.01 \mathrm{M} \\
\mathrm{Mg}\left(\mathrm{BH}_{4}\right)_{2} \\
\kappa\left(\mathrm{mScm}^{-}\right. \\
1)\end{array}$ & $\begin{array}{c}0.05 \mathrm{M} \\
\mathrm{Mg}\left(\mathrm{BH}_{4}\right)_{2} \\
\kappa\left(\mathrm{mScm}^{-}\right. \\
1)\end{array}$ & $\begin{array}{c}0.01 \mathrm{M} \\
\mathrm{Mg}\left(\mathrm{BH}_{4}\right)_{2} \\
\kappa\left(\mathrm{mScm}^{-}\right. \\
1)\end{array}$ & 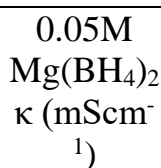 & $\begin{array}{c}0.01 \mathrm{M} \\
\mathrm{Mg}_{\left(\mathrm{BH}_{4}\right)_{2}} \\
\kappa\left(\mathrm{mScm}^{-}\right. \\
1)\end{array}$ & 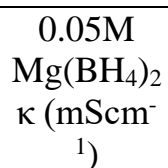 & $\begin{array}{c}0.01 \mathrm{M} \\
\mathrm{Mg}\left(\mathrm{BH}_{4}\right)_{2} \\
\kappa\left(\mathrm{mScm}^{-}\right. \\
1)\end{array}$ & $\begin{array}{c}0.05 \mathrm{M} \\
\mathrm{Mg}_{\left(\mathrm{BH}_{4}\right)_{2}} \\
\kappa\left(\mathrm{mScm}^{-}\right. \\
1)\end{array}$ \\
\hline 0 & 0.000 & 0.32 & 0.91 & 0.35 & 0.97 & 0.37 & 1.00 & 0.38 & 1.02 \\
\hline 15 & 0.125 & 0.51 & 1.13 & 0.53 & 1.15 & 0.56 & 1.17 & 0.56 & 1.21 \\
\hline 25 & 0.214 & 0.61 & 1.28 & 0.65 & 1.30 & 0.66 & 1.32 & 0.67 & 1.35 \\
\hline 50 & 0.448 & 0.83 & 1.58 & 0.87 & 1.64 & 0.90 & 1.68 & 0.92 & 1.72 \\
\hline 75 & 0.710 & 0.77 & 1.45 & 0.80 & 1.47 & 0.82 & 1.53 & 0.84 & 1.57 \\
\hline 85 & 0.822 & 0.58 & 1.20 & 0.62 & 1.26 & 0.62 & 1.31 & 0.64 & 1.35 \\
\hline 100 & 1.000 & 0.15 & 0.67 & 0.19 & 0.72 & 0.21 & 0.75 & 0.22 & 0.80 \\
\hline
\end{tabular}


Table 5: Experimental Conductivity ( $\kappa)$ for DGM-PC Binary Mixtures at $298.15 \mathrm{~K}$

\begin{tabular}{|c|c|c|c|c|c|}
\hline $\begin{array}{c}\text { DGM } \\
(\%)\end{array}$ & $\mathrm{X}_{1}$ & $\begin{array}{c}0.01 \mathrm{M} \\
\mathrm{Mg}\left(\mathrm{BH}_{4}\right)_{2} \\
K\left(\mathrm{mScm}^{-1}\right) \\
\end{array}$ & $\begin{array}{c}0.05 \mathrm{M} \\
\mathrm{Mg}\left(\mathrm{BH}_{4}\right)_{2} \\
K\left(\mathrm{mScm}^{-1}\right) \\
\end{array}$ & $\begin{array}{c}0.10 \mathrm{M} \\
\mathrm{Mg}\left(\mathrm{BH}_{4}\right)_{2} \\
K\left(\mathrm{mScm}^{-1}\right) \\
\end{array}$ & $\begin{array}{c}0.50 \mathrm{M} \\
\mathrm{Mg}\left(\mathrm{BH}_{4}\right)_{2} \\
K\left(\mathrm{mScm}^{-1}\right) \\
\end{array}$ \\
\hline 0 & 0.000 & 0.39 & 1.08 & 1.38 & 4.77 \\
\hline 15 & 0.095 & 0.60 & 1.30 & 1.73 & 5.42 \\
\hline 25 & 0.167 & 0.78 & 1.47 & 1.97 & 5.74 \\
\hline 50 & 0.374 & 1.10 & 1.85 & 2.3 & 6.03 \\
\hline 75 & 0.643 & 0.98 & 1.64 & 2.13 & 5.67 \\
\hline 85 & 0.772 & 0.80 & 1.47 & 1.92 & 5.36 \\
\hline 100 & 1.000 & 0.27 & 0.89 & 1.28 & 4.54 \\
\hline
\end{tabular}

Table 6: Experimental Conductivity $(\kappa)$ for DGM-PC Binary Mixtures at different temperatures

\begin{tabular}{|c|c|c|c|c|c|c|c|c|c|}
\hline \multirow[b]{2}{*}{$\begin{array}{c}\text { DGM } \\
(\%)\end{array}$} & \multirow[b]{2}{*}{$\mathrm{X}_{1}$} & \multicolumn{2}{|c|}{$308.15 \mathrm{~K}$} & \multicolumn{2}{|c|}{$318.15 \mathrm{~K}$} & \multicolumn{2}{|c|}{$328.15 \mathrm{~K}$} & \multicolumn{2}{|c|}{$338.15 \mathrm{~K}$} \\
\hline & & $\begin{array}{c}0.01 \mathrm{M} \\
\mathrm{Mg}\left(\mathrm{BH}_{4}\right)_{2} \\
\kappa\left(\mathrm{mScm}^{-}\right. \\
1)\end{array}$ & $\begin{array}{c}0.05 \mathrm{M} \\
\mathrm{Mg}\left(\mathrm{BH}_{4}\right)_{2} \\
\kappa\left(\mathrm{mScm}^{-}\right. \\
1)\end{array}$ & $\begin{array}{c}0.01 \mathrm{M} \\
\mathrm{Mg}\left(\mathrm{BH}_{4}\right)_{2} \\
\kappa\left(\mathrm{mScm}^{-}\right. \\
1)\end{array}$ & $\begin{array}{c}0.05 \mathrm{M} \\
\mathrm{Mg}\left(\mathrm{BH}_{4}\right)_{2} \\
\kappa\left(\mathrm{mScm}^{-}\right. \\
1)\end{array}$ & $\begin{array}{c}0.01 \mathrm{M} \\
\mathrm{Mg}\left(\mathrm{BH}_{4}\right)_{2} \\
\kappa\left(\mathrm{mScm}^{-}\right. \\
1)\end{array}$ & 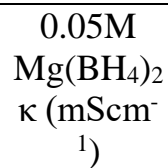 & $\begin{array}{c}0.01 \mathrm{M} \\
\mathrm{Mg}\left(\mathrm{BH}_{4}\right)_{2} \\
\kappa\left(\mathrm{mScm}^{-}\right. \\
1)\end{array}$ & 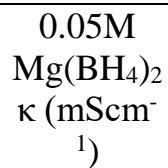 \\
\hline 0 & 0.000 & 0.39 & 1.11 & 0.43 & 1.15 & 0.45 & 1.21 & 0.47 & 1.27 \\
\hline 15 & 0.095 & 0.62 & 1.36 & 0.66 & 1.41 & 0.69 & 1.46 & 0.72 & 1.51 \\
\hline 25 & 0.167 & 0.80 & 1.52 & 0.83 & 1.60 & 0.86 & 1.67 & 0.89 & 1.71 \\
\hline 50 & 0.374 & 1.11 & 1.89 & 1.13 & 1.95 & 1.15 & 2.00 & 1.18 & 2.07 \\
\hline 75 & 0.643 & 0.99 & 1.68 & 1.00 & 1.72 & 1.03 & 1.78 & 1.07 & 1.85 \\
\hline 85 & 0.772 & 0.83 & 1.50 & 0.83 & 1.54 & 0.85 & 1.60 & 0.88 & 1.68 \\
\hline 100 & 1.000 & 0.29 & 0.92 & 0.30 & 0.97 & 0.33 & 1.02 & 0.36 & 1.08 \\
\hline
\end{tabular}

Table 7 Calculated Values of Dielectric Constant at Different Solvent Compositions

\begin{tabular}{ccccc}
\hline \multirow{2}{*}{ Composition (\%) } & \multicolumn{2}{c}{ DME } & DGM \\
\cline { 2 - 5 } & $X_{1}$ & Dielectric Constant & $X_{1}$ & Dielectric Constant \\
\hline 0 & 0.000 & $65.00^{(\mathrm{a})}$ & 0.000 & $65.00^{(\mathrm{a})}$ \\
15 & 0.125 & 56.33 & 0.095 & 56.40 \\
25 & 0.214 & 50.55 & 0.167 & 50.66 \\
50 & 0.448 & 36.10 & 0.374 & 36.33 \\
75 & 0.710 & 21.65 & 0.643 & 21.99 \\
85 & 0.822 & 15.87 & 0.772 & 16.25 \\
100 & 1.000 & $7.20^{(\mathrm{b})}$ & 1.000 & $7.65^{(\mathrm{c})}$ \\
\hline \multicolumn{2}{c}{ a: Payne \& Theodorou, 1972; b: Carvajal et al., 1965; c: Tang \& Zhao, 2014 }
\end{tabular}

\subsection{Conductivity}

Conductivity studies on solutions reflect the contributions from different factors namely: the level of ionic concentration, measure of dielectric constant and viscosity behavior of electrolyte systems (Ibezim-Ezeani et al., $2017 \mathrm{~b})$. It is clear from tabulated results that the conductivity of dilute $\mathrm{Mg}\left(\mathrm{BH}_{4}\right)_{2}$ electrolyte increased with increase in DME (Tables 3 and 4) and DGM (Tables 5 and 6) for constitution range of $0-50 \%$ vol. at the experimental temperatures. This is credited to lower viscosity of the binary mixture which enhanced ion mobility. Above the $50 \%$ vol. composition, a progressive drop in conductivity was recorded, which may be attributed to the effect of decreased dielectric constant of the binary mixture. Conductivity values were higher for DGM-PC mixture in comparison to those for DME-PC mixture; this is likely caused by improved solvation of $\mathrm{Mg}^{2+}$ in the mixture, due to stronger coordination with the tridentate $\mathrm{O}_{2}$ of DGM. It was observed that conductivity values for both DGM-PC and DME-PC mixtures increased with salt concentration (Tables 3 to 6). The composition range of $0-50 \%$ vol. for DME and DGM afforded favorable dielectric conditions (Table 7), permitting marginal rise in the degree of ionization with concentration until the composition range of 75 - $100 \%$ vol. for DME and DGM; 
where electrostatic forces become appreciable and conductivity values begin to decline. In low salt concentration of electrolytes, $\mathrm{Mg}^{2+}$ is synchronized with $\mathrm{O}_{2}$ of ether and develop large solvation shell distinct from anions, resulting in their relatively lower mobility; while in high concentration electrolytes characterized by small solvation shell, the mobility of $\mathrm{Mg}^{2+}$ is higher (Suo et al., 2013).

From Table 7, it was obvious that the dielectric constant of the mixtures decreased with increase in DME and DGM components. Increasing DGM or DME proportion in the binary system reduces the dielectric constant of the mixture and facilitates the creation of ion-pairs in the solution phase. This means that in solvents of low dielectric constants, having diminutive ionizing influence on electrolytes, the electrostatic forces between oppositely charged ions would be substantial and conductance will have diminutive value (Bhattarai et al., 2011). However, solvents of high dielectric constants afford better conducting solutions. With reference to Tables 3 to 6 , conductivity increased with temperature by dint of the combination of decreased viscosity of the solution, increased speed of the ions and increased dissociation levels. The dielectric constant is one of several properties that affect ion-pair formation, and decrease in dielectric constant forces conductivity to drop. This effect is more pronounced above the constitution range of $50 \%$ vol. for DME and DGM.

\section{Conclusions}

The density, viscosity and conductivity relationship between 0 - $100 \%$ vol. of DME-PC (or DGM-PC) and concentrations $(0.01,0.05,0.10$ and $0.50 \mathrm{M})$ of $\mathrm{Mg}\left(\mathrm{BH}_{4}\right)_{2}$ have been investigated at temperatures of 298.15, $308.15,318.15,328.15$ and $338.15 \mathrm{~K}$.

The viscosity data at different mole ratios of DME-PC (or DGM-PC) and concentrations of $\mathrm{Mg}\left(\mathrm{BH}_{4}\right)_{2}$ were correlated satisfactorily using Jones-Dole equation. The A coefficient values increased as the \% composition of DME (or DGM) increased; while the B coefficient values were more positive than the corresponding values of A coefficient for the studied systems. Hence, the superior strength of ion-dipole interaction over dipole-dipole interaction facilitated stability of solvated $\mathrm{Mg}\left(\mathrm{BH}_{4}\right)_{2}$ coordination complexes in solution. Thus, a stable $\mathrm{Mg}\left(\mathrm{BH}_{4}\right)_{2}$ coordination structure may be unproblematic to form in the course of $\mathrm{Mg}$ stripping, which will benefit the stripping process and enhance the coulombic efficiency. Generally, there was systematic increase in conductivity values of DME (or DGM) with increase in temperature (from 298.15 to $338.15 \mathrm{~K}$ ) and $\mathrm{Mg}\left(\mathrm{BH}_{4}\right)_{2}$ concentrations $(0.01$ to $0.50 \mathrm{M})$ in each system. However, the conductivity values of DGM-PC were higher than those of DMEPC in all cases; and increased from 0 - $50 \%$ composition, followed by decreased conductivity values from 75 $100 \%$ vol. (DME or DGM). The results from this study show that the prime ratio for optimal battery functionality and reversibility is $50 \%$ vol. of DME-PC (or DGM-PC) components.

\section{References}

Aurbach, D., Moshkovich, M., Schechter, A., \& Turgeman, R. (2001 a). A comparison between the electrochemical behaviour of reversible magnesium and lithium electrodes. Journal of Power Sources, $97-$ 98: 269-273.

Aurbach, D., Schechter, A., Moshkovich M., \& Cohen, Y. (2001 b). Mechanisms of Reversible Magnesium Deposition Processes. Journal of The Electrochemical Society, 148(9), A1004-A1014.

Bhattarai, A., Sapkota, D., Subedi, N. P., Khanal, M. \& Niraula, T. P. (2011). Conductance of sodium nitrate in methanol-water mixtures at different temperatures. Nepal Journal of Science \& Technology, 12, 187-192.

Bremer, M., Linti, G., Noth, H., Thomann-Albach, M., \& Wagner, G. (2005). Metal Tetrahydroborates and Tetrahydroborato Metalates. 30 [1] Solvates of Alcoholato-, Phenolato-, and Bis(trimethylsilyl)amidoMagnesium Tetrahydroborates $\mathrm{XMgBH}_{4}(\mathrm{Ln})$. Journal of Inorganic and General Chemistry, 631(4), 683697.

Carvajal, C., Tolle, K. J., Smid J., \& Szwarc, M. (1965). Studies of solvation phenomena of ions and ion pairs in Dimethoxyethane and Tetrahydrofuran. Journal of the American Chemical Society, 87, 5548-5553.

Chatt, J. (1968). Hydrides, hydrogen bonding and dihydrogen activation. In G. J. Leigh, \& N. Winterton (Eds.), Modern coordination chemistry: The legacy of Joseph Chatt (pp. 31-43, 416). Cambridge: Royal Society of Chemistry.

Hannan, M. A., Hoque, M. M., Mohamed A., \& Ayob, A. (2017). Review of energy storage systems for electric vehicle applications: Issues and challenges. Renewable and Sustainable Energy Reviews, 69, 771-789. 
Ibezim-Ezeani, M. U., Menegbo, L. I., \& Abia, A. A. (2017 a). Physico-chemical and mixing parameters of electrolyte systems containing 1,2 Dimethoxyethane and Ethylene carbonate. International Journal of Emerging Technology \& Advanced Engineering, 7(2), 9-14.

Ibezim-Ezeani, M. U., Menegbo, L. I., \& Abia, A. A. (2017 b). Characteristic behavior of Lithium and Magnesium Perchlorate salts in binary organic systems followed conductometrically. International Journal of Scientific and Engineering Research, 5(3), 13-16.

Jones, G. \& Dole, M. (1929). The viscosity of aqueous solutions of strong electrolytes with special reference to barium chloride. Journal of the American Chemical Society, 51(10), 2950-2964.

Kotera, K., Suzuki, K., Matsumura, K., Nakano, K., Oyama, T. \& Kambayashi, U. (1962). Dipole moments of polyethylene glycol diethyl ethers. Bulletin of the Chemical Society of Japan, 35, 797-801.

Mohtadi, R., Matsui, M., Arthur, T. S., \& Hwang, S. J. (2012 a). Magnesium borohydride: from hydrogen storage to magnesium battery. Angewandte Chemie International Edition, 51(39), 9780-9783.

Mohtadi, R., \& Mizuno, F. (2014). Magnesium batteries: current state of the art, issues and future perspectives. Beilstein Journal of Nanotechnology, 5, 1291-1311.

Mohtadi, R., Sivasubramanian, P., Hwang, S-J., Stowe, A., Gray, J., Matsunaga, T. \& Zidan, R. (2012 b). Alanate-borohydride Material Systems for Hydrogen Storage Applications. International Journal of Hydrogen Energy, 37(3), 2388-2390.

Muldoon, J., Bucur, C. B., Oliver, A. G., Sugimoto, T., Matsui, M., Kim, H. S., Allred, G. D., Zajicek, J., \& Kotani, Y. (2012). Electrolyte roadblocks to a magnesium rechargeable battery. Journal of Energy and Environmental Science, 5(3), 5941-5950.

Payne, R., \& Theodorou, I. (1972). Dielectric properties and Relaxation in Ethylene Carbonate and Propylene Carbonate. Journal of Physical Chemistry, 76, 2892-2900.

Pour, N., Gofer, Y., Major, D. T. \& Aurbach, D. (2011). Structural analysis of electrolyte solutions for rechargeable $\mathrm{Mg}$ batteries by stereoscopic means and DFT calculations. Journal American Chemical Society, 133(16), 6270-6278.

Rohdewald, P., \& Molder, M. (1973). Dielectric constants of amide-water systems. Journal of Physical Chemistry, 77(3), 373-377.

Smith, D.G., Jaffe, R. L., \& Yoon, D. Y. (1995). Conformations of 1,2-Dimethoxyethane in the Gas and Liquid Phases from Molecular Dynamics Simulations. Journal of the American Chemical Society, 117(1), 530531.

Stokes, R. H., \& Mills, R. (1965). The International Encyclopedia of Physical Chemistry and Chemical Physics, London: Pergamon.

Suo, L., Hu, Y., Li, H., Armand, M. \& Chen, L. (2013). A new class of solvent-in-salt electrolyte for high-energy rechargeable metallic lithium batteries. Nature Communications, 4(1481), 1-9.

Tang, S., \& Zhao, H. (2014). Glymes as versatile solvents for chemical reactions and processes: from the laboratory to industry. Royal society of Chemistry Advances, 4, 11251-11287. 